\title{
Hard-female mating in the brachyuran crab Thalamita prymna (Portunidae)
}

\section{Christopher P. Norman, Yoshiaki J. Hirano, and Tatsuo Miyazaki}

\begin{abstract}
Intermolt (hard shelled) female Thalamita prymna, including ovigerous females, were observed to mate both in the field $(N=2)$ and laboratory $(N=13)$. In the laboratory, intermolt males and females showed characteristic stalking and maneuvering behaviors prior to copulation, with copulation lasting $34.5 \pm 2.4$ minutes (mean $\pm \mathrm{SD}$ ). During a 20 month field survey, no guarding behavior or sperm plugs which are characteristic of portunid soft-female mating behavior were observed. A female reared in isolation to maturity over a 6 month period from an immature instar successfully mated during the intermolt stage and produced a fertile egg brood ten days after the single mating. From these observations, hard-female mating is concluded to be the principal mating strategy in T. prymna. Females of the congeneric species $T$. sima also mate during the intermolt and the contrasting mating behaviors of these 2 species are discussed.
\end{abstract}

\section{Introduction}

Two basic patterns of mating occur in brachyuran crabs. These are a) softfemale mating, in which mating occurs immediately after the female molt, while the carapace of the female is still soft (soft shelled); and b) hard-female mating, in which mating occurs during the extended intermolt (hard shelled) period of the female molt cycle (Hartnoll, 1969; Sastry, 1983). Species of portunids which use soft-female mating show extensive pre- and postcopulatory guarding behaviors and sperm plugs [gelatinous material deposited in the female's vaginae during mating (Hartnoll, 1968; Christy, 1987)]. Guarding ensures that females are protected during their vulnerable molting period, while males gain exclusive paternity of the offspring during the ensuing intermolt period of the females (Hartnoll, 1968, 1969; Christy, 1987). Although previously only soft-female mating had been reported for portunids (Hard, 1942; Cheung, 1966; Ryan, 1966; Heasman et al., 1985; Norman \& Jones, 1993; Haddon, 1994), Norman (1996) showed evidence for hard-female mating in the portunid Thalamita sima $\mathrm{H}$. Milne Edwards. Norman suggested that hard-female mating in this small sized portunid in which matings are quick (1-2 minutes duration) may minimize the risk of predation.

Thalamita species are generally small, with the larger species of the genus only approximating $70 \mathrm{~mm}$ carapace width (CW), e.g., T. crenata (Latreille) and $T$. prymna (Herbst) (Thomas et al., 1987; Norman, 1993). Thalamita prymna is a locally abundant species in rocky areas from the low water mark to approximately $20 \mathrm{~m}$ depth. It occurs along the southern coast of Japan from Tokyo Bay to Okinawa (Sakai, 1976) and is also reported from South Africa (Barnard, 1950), Australia (Stephenson \& Hudson, 1957) and the Philippines (Sakai, 1976). Here we describe field and laboratory observations of the mating behaviour of T. prymna. 


\section{Materials and Methods}

1) Field Observations - SCUBA samples of $T$. prymna were taken over a 20 month period (May 1990 - December 1991) approximately twice a week adjacent to the Banda Marine Laboratory, Tokyo University of Fisheries (34 ${ }^{\circ} 58^{\prime}$ $3 " \mathrm{~N}, 139^{\circ} 46^{\prime} 5^{\prime \prime E}$ ). Detailed descriptions of the sampling procedure and the surveyed rock reef area are given elsewhere (Norman, 1993, 1996; Norman et al., 1994). Thalamita prymna were captured by hand from the shallow reef ( 0 to $8 \mathrm{~m}$ ) and brought to the laboratory for examination. Parameters recorded include: sex, carapace width (CW) (between the tips of the 5th anterolateral spines), reproductive state (ovigerous, presence of sperm plugs protruding from the vulvae) and molt cycle stage [determined using criteria of Drach \& Tchernigovtzeff (1967) into (A) postmolt, (B) papershell, (C) intermolt and (D) premolt]. Approximately 20 eggs were removed from ovigerous females and staged as: stage I, newly spawned, full of yolk, no cleavage; stage II, cleavage, but lacking eyespot pigmentation, stage III, eyespot pigmentation visible, but lacking chromatophore pigmentation; stage IV, chromatophores clearly visible. Ovaries of ovigerous females with eggs in stages III or IV were classified into $i$ ) immature/spent/early developing - ovaries flaccid, small in size ( $<0.5 \mathrm{~g})$, translucent or pale colored; ii) maturing - ovaries conspicuous ( $>0.5 \mathrm{~g}$ ) yellow to orange, oocytes $>100 \mu \mathrm{m}$; $i i i)$ ripe - large ovaries covering the hepatopancreas, oocytes well packed and $>200 \mu \mathrm{m}$. From realizing that 'normal' portunid mating behaviour may not be shown by $T$. prymna (June 1990) care was taken to detail any guarding, territorial and molting behaviors observed in the field.

2) Laboratory Observations - Laboratory observations were carried out at Kominato Marine Laboratory, Chiba
University $\left(35^{\circ} 07^{\prime} 02^{\prime \prime} \mathrm{N}, 140^{\circ} 11^{\prime} 20^{\prime \prime} \mathrm{E}\right)$ during May and June 1997. Crabs were collected from the shallow sublittoral at Kominato and maintained in the laboratory in $10 l$ tanks with constant throughflow of sea water. Males were kept for approximately 1 week prior to mating to standardize their reproductive condition, but females were maintained overnight prior to pairing them in a $30 l$ round tank. Observations were carried out during the day and crabs were fed to satiation on krill prior to placement in the $30 l$ tank in which a constant through flow of sea water (3 l/min) was maintained. An approximately round stone (15 $\mathrm{cm}$ diameter) was placed in the center of the tank to allow a degree of refuge. A single male and single female were introduced into the tank at the same time and were subsequently observed for 2 hours. The mating tank was cleaned with fresh water and dried before each mating trial to reduce the chance of transferring chemical stimuli from one trial to another. Females that did not initially mate within the 2 hour period, were again placed in the mating tank on the following 2 days each time with a different male. If they did not mate during any of the 3 trials, then they were recorded as 'failed to mate' in Table 1. Females that mated successfully were retested after various periods with either the same or different males. However due to the low frequency of successful re-matings and constraints of space, re-matings were limited to a 14 day period. Behaviors were divided into 'stalking time', the time required prior to the male seizing the female; 'maneuvering time', the time required from seizing the female to the female becoming passive in an inverted position underneath the male; and 'copulatory period', the length of time in copula until mating was terminated. Termination of copulation was characteristically abrupt, with the female changing from being passive to actively pushing away 
from the male using her walking and swimming legs. Typically only a few seconds passed from when the female became active to release from the mating position.

3) Reared Females - Using the procedure described in Norman (1996) to determine if viable embryos are produced during the female intermolt period following a single copulation, we reared immature female $T$. prymna in isolation. Immature females $(N=10)$ of $15-25 \mathrm{~mm} \mathrm{CW}$ [sexual maturity is estimated to occur between 35 to $40 \mathrm{~mm} \mathrm{CW}$ (Norman, 1993)] were collected in October and November 1996 and individually reared over the ensuing winter and spring period until maturity in $10 l$ tanks with a constant through-flow of sea water. From April 1997 the bottom of the tanks were covered with a 1-2 cm layer of sand to enhance egg adhesion (Ryan, 1967). Sand was replaced weekly. Individuals were fed to excess every other day on krill or opened Mytilus sp. Uneaten material was removed on the following day. Females were examined every other day from May (start of the ovigerous season) for the presence of eggs.

\section{Results}

1) Field Observations - From 170 dives over the 20 month period at Banda, a total of $931 \mathrm{~T}$. prymna (males 478; females 453) were collected from the rock reefs. Maximum sizes were: male, 73.4 $\mathrm{mm}$ CW; female, $68.6 \mathrm{~mm} \mathrm{CW}$. The smallest ovigerous female was $35.2 \mathrm{~mm} \mathrm{CW}$. No pre- or postmolt copulatory guarding was observed in the field and no sperm plugs were observed in females ( $>35 \mathrm{~mm}$ CW) in either postmolt (soft shelled, stage $\mathrm{A} ; N=3$ ) or papershell (shell hardening, stages $\mathrm{B} ; N=19)$. During the 20 month survey at Banda and the observations at Kominato only two pairs in copula (female inverted underneath the male) were observed (June 1990 and May 1997), both being observed during daylight hours. For the June 1990 observation only the female was collected (non-ovigerous, intermolt female $37.2 \mathrm{~mm} \mathrm{CW}$ ), while for the 1997 observation both specimens were collected, the female (48.3 $\mathrm{mm} \mathrm{CW}$ ) was ovigerous (Stage II eggs) and in intermolt, copulating with a male of $50.0 \mathrm{~mm} \mathrm{CW}$. In both field observations in copula pairs were observed in relatively exposed positions at the mouth of broad crevices on the reef surface.

In 1991 ovigerous females were observed from May to July and in 1990 in June and July (Fig. 1). Over both of these periods however the percentage of mature females that were ovigerous per month was low $(75.0 \%$ \& $35.7 \%$ in June \& July 1990 and $13.3 \%, 38.5 \%$ \& $17.6 \%$ in May, June \& July 1991, respectively), with June of both years showing peak percentage ovigerous. Of the ovigerous females with stage III or IV eggs in June ( $N=7$; data for both years combined) 4 specimens had maturing stage ovaries indicating that at least some females produce multiple broods. The remaining females had spent/early developing ovaries as did the ovigerous females in July $(N=3)$.

2) Laboratory Observations - Table 1 details our observations on the crabs that copulated in the laboratory. In successful pairings, copulation invariably required an extended period of time [34.5 \pm 2.4 minutes (mean $\pm \mathrm{SD}$ ), $N=13$; Table 1]. Both ovigerous (Pair Nos. 5, 7, 9, 10 \& 12) and non-ovigerous intermolt (molt stage C; Pair Nos. 1, 2, 3, 4, 8, 11 \& 13) females mated. The papershell molt stage (B stage) female (Pair No. 6) failed to mate as did 2 stage I ovigerous females (Pair Nos. 14 \& 16). Females that had previously mated, subsequently did not readily re-mate. Of 20 re-matings (data not given) within 14 days of the initial mating with the same or different males, only 3 led to copulation (Pair Nos. 8, 9 \& 10).

Crabs mated even when the female 

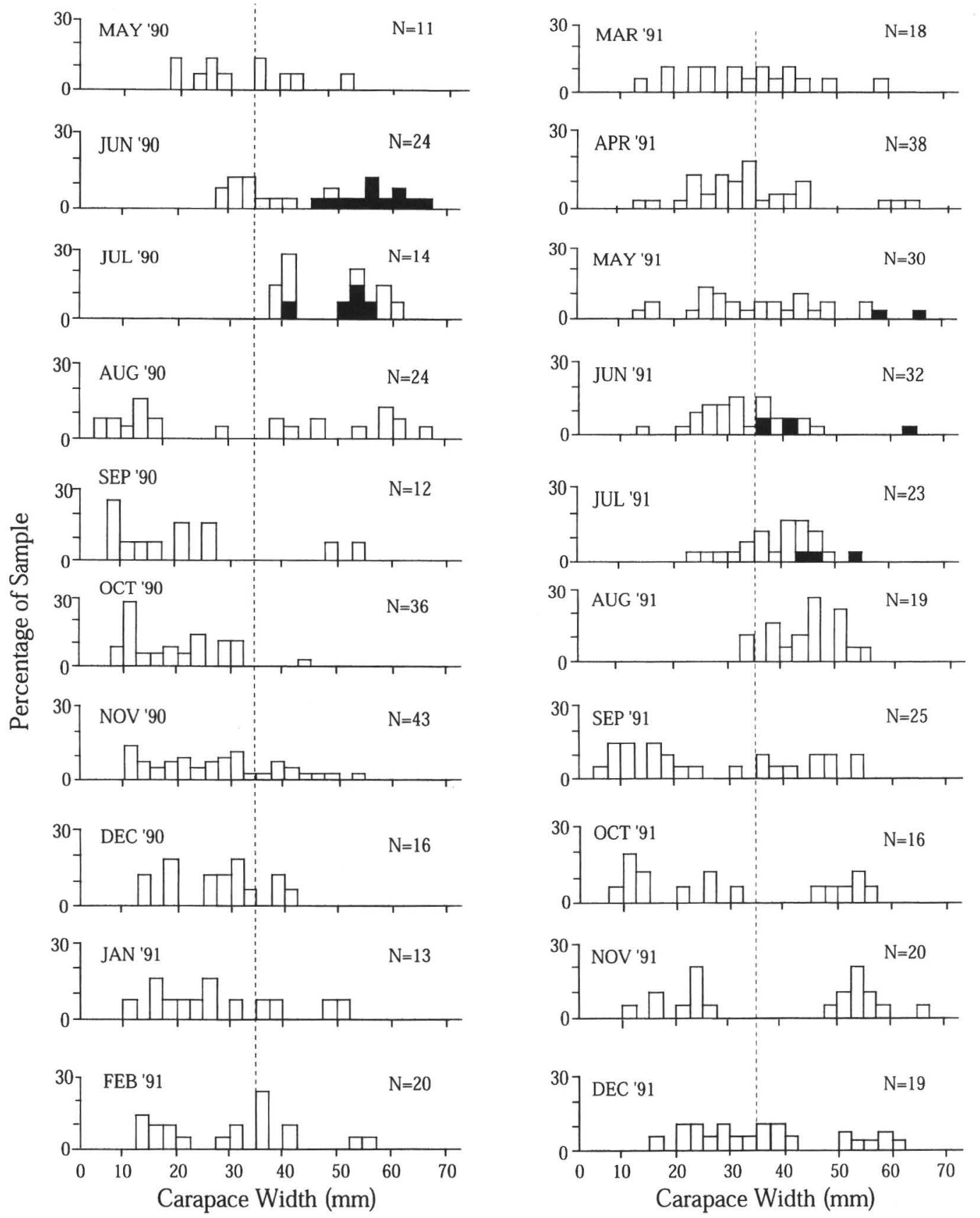

Fig. 1. Size frequency histograms in $2.5 \mathrm{~mm}$ intervals for female Thalamita prymna from May 1990 to December 1991. Black bars indicate ovigerous females and dotted lines at $35 \mathrm{~mm} \mathrm{CW}$ the estimated size of sexual maturity. 
Table 1. Mating period (minutes) of laboratory mating in Thalamita prymna.

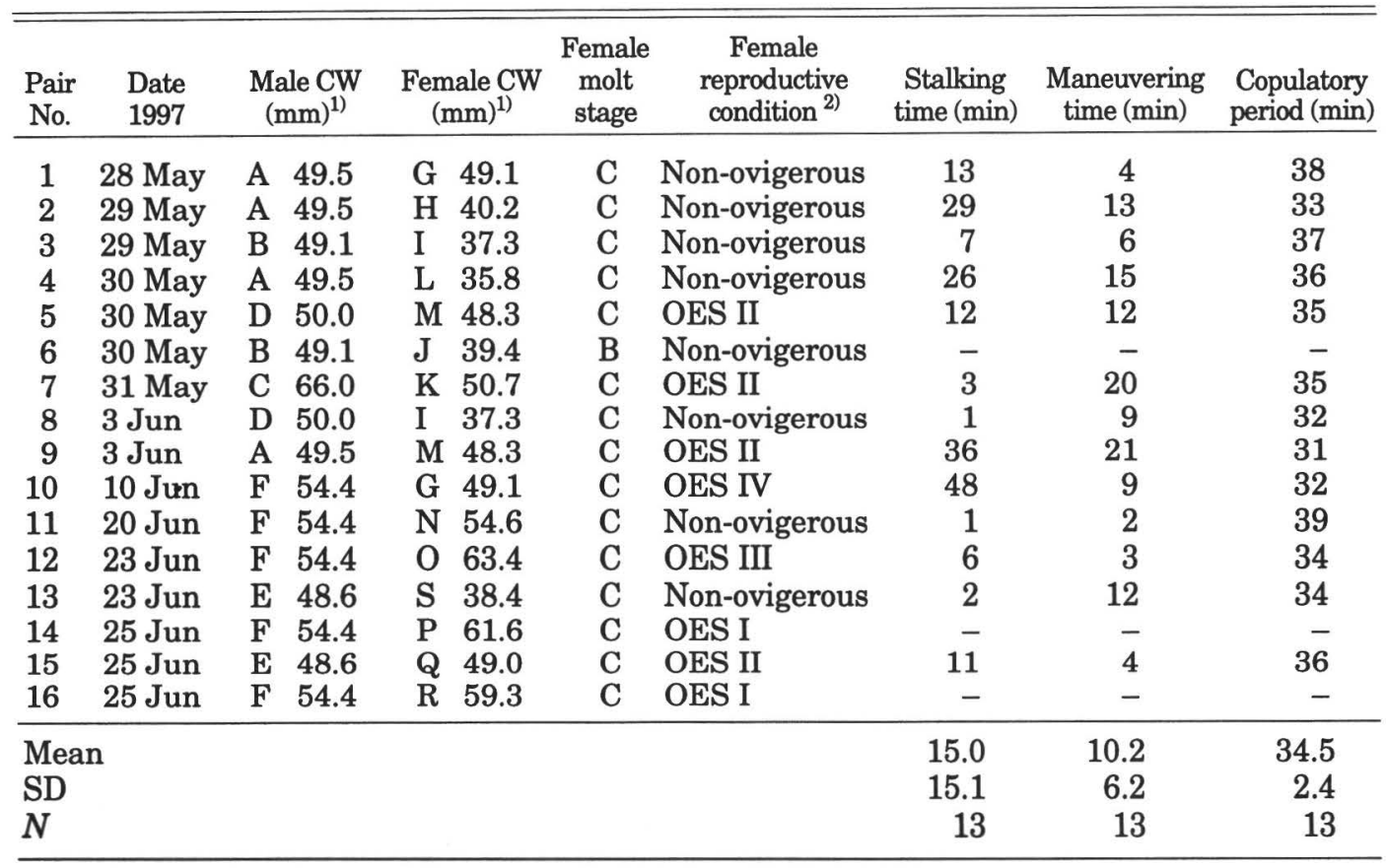

- indicates failed to mate after 2 hours of observation.

1) Upper case letters indicate code number for each individual.

2) OES indicates 'Ovigerous Egg Stage'.

was considerably larger than the male (Pair No. 12). The mating position seen in all matings was with the male above the female, i.e., a typical portunid mating stance (see Cheung, 1966), with the female in an inverted position, carried underneath the male.

Typically, on being released into the mating tank, both crabs moved to the centrally placed rock so that their posterior was held against the rock. The male, still with its posterior to the rock, would approach the female and the female generally moved away. This approaching by the male and withdrawing by the female would generally recur several times until the male moved away from the rock and approached the female more directly, either from the side or head-on. This stalking behavior by the male and moving away by the female continued until either the female allowed the male to take hold one of her walking legs with his cheliped or the male aborted this behavior and returned to a position with its posterior held against the rock and did not move towards the female. In general the stalking behavior can be described as 'cautious' with minimal rapid movements by either male or female. The grasping of the female's walking leg and other interactions were distinctly non-aggressive. The time required for this behavior of stalking varied markedly among the pairs tested (15.0 \pm 15.1 minutes; Table 1). For pair numbers $7,8 \& 11$ the male was able to take hold of the female almost immediately on placement in the tank, this probably being an artifact of the experimental method of introducing both crabs at the same time. Once the walking leg of the female was seized, the male would then maneuver the female into the mating position. During this behavior, the female 
invariably resisted and a degree of coercion was required to initiate mating. During maneuvering the male when holding the female with both chelipeds pacified the female by rhythmic pushing motions, or if holding the female with only one cheliped by cradling the female with the free cheliped. The period of this behavior also varied between pairs $(10.4 \pm 6.5$ minutes; Table 1). Once positioned under the male, the female would become passive and from this point the copulatory period was measured until the pairing was terminated by the female breaking away from the male.

3) Reared Females - Of the 10 immature females originally collected and reared in isolation only 3 successfully molted to a mature size while in captivity. None of the females produced a sterile brood as reported in the congeneric species T. sima (Norman, 1996), but one specimen, after the single mating on the 28 May 1997 (Pair No. 1; Table 1), produced a fertile brood on the 7 June, 1997, 10 days after mating and the brood hatched on the 1 July 1997 (water temperature ranging over the 25 day period from 19.5 to $21.8^{\circ} \mathrm{C}$ ). The other 2 females, although successfully mated (Pair Nos. 2 \& 3 ) did not ovulate in the laboratory.

\section{Discussion}

In portunid soft-female mating, characteristic pre- and post-copulatory guarding and sperm plugs occur (Hartnoll, 1968, 1969). In this study, during the 20 month field survey no guarding behavior or sperm plugs were observed in T. prymna, and only intermolt females (hard-female mating) were observed to mate both in the field $(N=2)$ and laboratory $(N=13)$. An intermolt female which matured in isolation, mated only once while in intermolt and produced a fertile brood 10 days later. Further, a postmolt (molt stage B) female did not initiate a mating response in males in the laboratory. Thalamita prymna therefore appears able to successfully mate while the female is in intermolt (hard-female mating) and based on the lack of guarding behaviour, sperm plugs and mating response to the postmolt female, hard-female mating appears to be the principal mating behavior in this species.

The copulatory period was remarkably constant in this species $(34.5 \pm 2.4$ minutes; $N=13$ ), this being the case even for males that re-mated with different females on consecutive days (i.e., Male A; Pair Nos. 1, 2 \& 4). This suggests that males are capable of complete repeat matings within a short period of time. Females however generally did not re-mate with the same or different males within the 14 day period with the exception of 3 specimens (G, I \& M). For these specimens, with the exception of Female I which was grasped almost immediately on placement in the tank (Pair No. 8, see Results section), they required longer 'stalking time' and for all 3 specimens, marginally shorter 'copulation period' than average. However all females, except for ovigerous females with stage I eggs and the molt stage $B$ female, mated within the 3 day trial period in the laboratory, suggesting that the mating frequency in the field is low.

Although $T$. prymna and $T$. sima are similarly sized (maximum sizes approximately 70 and $60 \mathrm{~mm} \mathrm{CW}$, respectively; Norman, 1993) and both show hardfemale mating behavior, the mating behavior of the two species differs markedly. The copulatory period in $T$. prymna was long and was preceded by considerable periods of 'stalking' and 'maneuvering' by the male. In contrast, the mating behavior in T. sima is invariably rapid; copulation lasts less than 2 minutes, and typically mating occurs within 5 minutes of being placed together in the mating tank (Norman, 1996). Further, receptive T. sima 
females would re-mate several hours after a mating, this being with the same male or a different male. Ovigerous females of $T$. sima occur from April to October, with laboratory reared females producing up to 7 broods over this extended period (Norman, 1996). In this study, T. prymna appears to have a shorter ovigerous season (May-July) with the number of broods appearing to be more limited with some females capable of having at least 2 broods per season. Further, the mating stance adopted during copulation also varied between the species, with $T$. sima using various stances depending on the relative sizes on the male and the female (Norman, 1996). In $T$. prymna only the male above stance, typical of other portunids (see Cheung, 1966), was observed even when the female in the mating pair was substantially larger than the male (i.e., Pair No. 12).

The copulation period in particular is very different between the 2 species and may be related to both behavioral and morphological differences. Morphologically, the vaginae of both species are of the simple duct pattern described by Hartnoll (1968), however the amount of sperm deposited, deposition rate and histological differences in the reproductive structures were beyond the scope of this study. Behaviorally, however, both the number of broods per spawning season and respective habitats vary between the species. Thalamita sima lives in the sandy margins of reefs, often burying itself into the sand for cover and showing minimal homing (Norman, unpublished data), but showing home range maintenance (Vannini \& Cannicci, 1995). Thalamita prymna occurs on the rock reef in crevices and holes in the rock and homes to specific locations on the reef (Norman, unpublished data). This habitat separation occurs both during the day and night, with $T$. prymna generally not being observed away from the rock face areas at night. As the sandy margins around the reefs generally interconnect, the extent of movement and encounter frequencies for $T$. sima are probably higher than for $T$. prymna, which particularly for crabs on more isolated rocks, may have more limited opportunity of mating. With high encounter rates, short matings may minimize predation, while in species with lower encounter rates a more complex mating behavior with a longer copulation period may ensure the successful transferal of sperm.

Research on portunid mating has generally focused on the larger commercial species, all of which use soft-female mating. Behaviors associated with softfemale mating, however, are to a certain extent, predictable due to the constraints imposed by the molt cycle of the female. For the hard-female mating portunid species of $T$. prymna and T. sima (Norman 1996), considerable variation in copulatory and associated mating behaviors occur and further comparative examination of trends in mating behavior both between and among species of the two mating types may highlight in terms of both phylogeny and ecology the diversity in this family.

\section{Acknowledgments}

We thank Drs. M. Omori, H. Yamakawa and Y. Koike for their encouragement during the field sampling at Banda and the staff of both the Banda Marine Laboratory of Tokyo University of Fisheries and the Kominato Marine Laboratory of Chiba University for their technical support. We also gratefully acknowledge S. Goshima and J. H. Christy for their constructive comments on the final draft of the paper.

\section{Literature Cited}

Barnard, K. H., 1950. Descriptive catalogue of South African decapod Crustacea. Annals 
of the South African Museum, 38: 1-837.

Cheung, T. S., 1966. An observed act of copulation in the shore crab, Carcinus maenas (L.). Crustaceana, 11: 107-108.

Christy, J. H., 1987. Competitive mating, mate choice and mating associations of brachyuran crabs. Bulletin of Marine Science, 41(2): 177-191.

Drach, P., \& Tchernigovtzeff, C. C., 1967. Sur la méthode de détermination des stades d'intermue et son application générale aux crustacés. Vie Milieu, série A: Biologie Marine, 18: 595-610.

Haddon, M., 1994. Size-fecundity relationships, mating behaviour, and larval release in the New Zealand paddle crab, Ovalipes catharus (White 1843) (Brachyura: Portunidae). New Zealand Journal of Marine and Freshwater Research, 28: 329334.

Hard, W. L. 1942. Ovarian growth and ovulation in the mature blue crab Callinectes sapidus Rathbun. Chesapeake Biological Laboratory Publications, 46: 3-17.

Hartnoll, R. G., 1968. Morphology of the genital ducts in female crabs. Journal of the Linnean Society of London, Zoology, 47: 279-300.

- 1969. Mating in the Brachyura. Crustaceana, 16: 161-181.

Heasman, M. P., Fielder, D. R., \& Shepherd, R. K., 1985. Mating and spawning in the mud crab, Scylla serrata (Forskål) (Decapoda: Portunidae), in Moreton Bay, Queensland. Australian Journal of Marine and Freshwater Research, 36: 773-783.

Norman, C. P., 1993. Ecology of the swimming crabs Thalamita sima H. Milne Edwards, 1834 and T. prymna (Herbst, 1803) - a field study of their reproductive strategies, parasite-host interactions and implications of limb loss. Ph.D. thesis, Tokyo University of Fisheries, Japan, $201 \mathrm{pp}$.

1996. Reproductive biology and evidence for hard-female mating in the brachyuran crab Thalamita sima (Portunidae). Journal of Crustacean Biology, 16(4): 656-662.

\& M. B. Jones. 1993. Reproductive ecology of the velvet swimming crab, Necora puber (Brachyura: Portunidae), at Plymouth. Journal of the Marine Biological
Association U. K., 73: 379-389.

- Yamakawa, H., \& Yoshimura, T., 1994. Habitat selection, growth rate and density of juvenile Panulirus japonicus (Von Siebold, 1824) (Decapoda, Palinuridae) at Banda, Chiba Prefecture, Japan. Crustaceana, 66: 366-383.

Ryan, E. P. 1966. Pheromone: evidence in a decapod crustacean. Science, 151: 340-341.

, 1967. Structure and function of the reproductive system of the crab Portunus sanguinolentus (Herbst) (Brachyura: Portunidae). II. The female system. Marine Biological Association of India, Symposium Series 2 (2): 522-544.

Sakai, T., 1976. Crabs of Japan and the Adjacent Seas. Kodansha, Tokyo [In 3 volumes: (1) English text, xxix +773 pp. (2) Plates volume, 16 pp., 251 pls. (3) Japanese text, 461 pp.].

Sastry, A. N., 1983. Ecological aspects of reproduction. In: F. J. Vernberg \& W. B. Vernberg, (eds.), The Biology of Crustacea, Volume 8. Academic Press, Inc., New York, 179-270.

Stephenson, W., \& Hudson, J. J., 1957. The Australian portunids (Crustacea; Portunidae). I. The genus Thalamita. Australian Journal of Marine and Freshwater Research, 8(3): 312-368.

Thomas, M., Ajmalkhan, S., Sriraman, K., \& Darnodaran, R., 1987. Age and growth of three estuarine portunid crabs Scylla serrata, Scylla serrata serrata and Thalamita crenata. Journal of the Marine Biological Association, India, 29: 154-157.

Vannini, M., \& Cannicci, S., 1995. Homing behaviour and possible cognitive maps in crustacean decapods. Journal of Experimental Marine Biology and Ecology, 193: 67-91.

Address: Kominato Marine Laboratory, Marine Ecosystems Research Center, Faculty of Science, Chiba University, AmatsuKominato-cho, Awa-gun, Chiba 299-55, Japan.

E-mails: (CPN) norman@earth.s.chiba-u.ac.jp; (YJH) hiranoyj@earth.s.chiba-u.ac.jp; (TM) myzkt@earth.s.chiba-u.ac.jp 